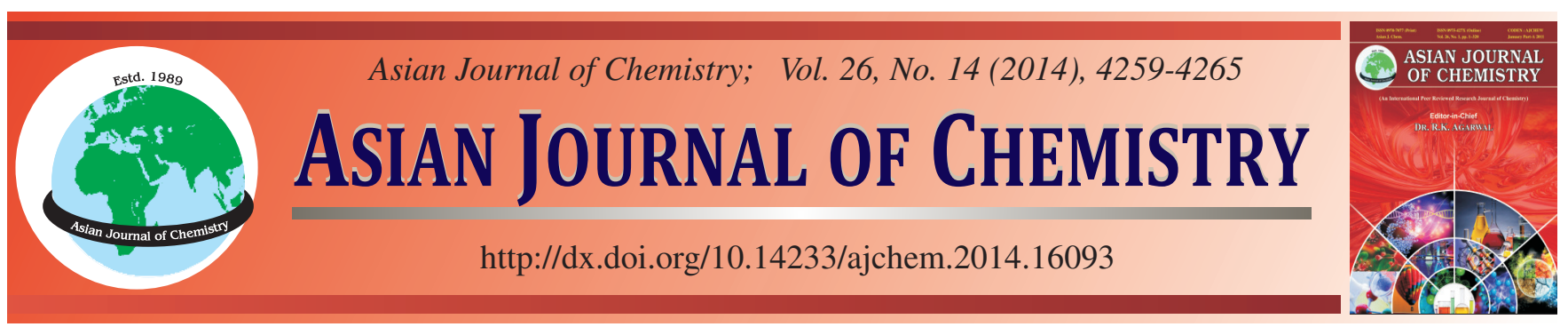

\title{
Molecular Structure, Vibrational Spectra, Theoretical NBO and HOMO-LUMO Analysis of Bi-Glycine Hydrobromide by DFT Method
}

\author{
N. Balamurugan ${ }^{1, *}$, C. Charanya ${ }^{2}$ and S. Sampathrrishnan ${ }^{3, *}$
}

${ }^{1}$ Department of Physics, PERI Institute of Technology, Chennai-600 048, India

${ }^{2}$ Department of Physics, Sri Venkateshwara College of Engineering, Sriperumbudur-602 117, India

${ }^{3}$ Department of Applied Physics, Sri Venkatashwara College of Engineering, Sriperumbudur-602 117, India

*Corresponding authors: E-mail: n_rishibalaa@yahoo.co.in; sambathk@svce.ac.in

\begin{abstract}
An organic non linear optical material of bi-glycine hydrobromide was successfully grown by slow evaporation method. The optimized molecular geometry, harmonic vibrational spectra, natural bond orbital (NBO) analysis, highest occupied molecular orbital and lowest un occupied molecular orbital, milliken atomic charge, thermodynamic properties of zero-point vibrational energies, rotational constants, dipole moment, entropies were calculated for the title compound by density functional B3LYP method with $6.31++\mathrm{G}(\mathrm{d}$,p) basis set using Gaussion $03 \mathrm{~W}$ program program package on a intel core i3/1.6 GHz personal computer. We also recorded the FT-IR, FT Raman spectra of bi-glycine hydrobromide at room temperature.
\end{abstract}

Keywords: Vibrational spectra, DFT, Natural bond orbital analysis, HOMO-LUMO, Bi-glycine hydrobromide.

\section{INTRODUCTION}

Bi-glycine hydrobromide (BGHB) and its derivatives play major role in the emerging photonic and optoelectronic technologies ${ }^{1-3}$ and telecommunications, frequency mixing, electro-optic modulation, optical parameter oscillator, optical bistability ${ }^{4,5}$, medicine, photochemistry ${ }^{6}$ and other applications. The investigation on the structure and fundamental vibrations of bi-glycine hydrobromide and its derivatives are still being carried out increasingly.

From the literature survey, which divulges that there is no $a b$ initio and density functional wave number calculation of Bi-glycine hydrobromide to the best of our knowledge. In the present study, we were using DFT method for the calculation of the geometric parameter and vibrational spectra of Bi-glycine hydrobromide. Along with bond order analysis, natural bond orbital (NBO) analysis, highest occupied molecular orbital (HOMO) and lowest unoccupied molecular orbital (LUMO) analysis, non-linear optical properties and thermodynamic properties of zero point vibrational energies, rotational constants, dipole moment and entropies were calculated for the title compound at B3LYP/6.31 ++G(d,p) level.

\section{EXPERIMENTAL}

High purity glycine salt (E. Merck) and hydrobromic acid (E. Merck) were taken in the molar ratio 2:1 in deionized water to synthesis bi-glycine hydrobromide salt. The saturated BGHB solution of $\mathrm{pH}$ value of 2 had been prepared using doubly recrystallized salt. The solution was filtered using sintered glass filter 1 micror porosity. The filtered solution was transferred into the petty disc and allowed to evaporate slowly at room temperature. Transparent and flawless crystals of size: $22 \mathrm{~mm} \times 6 \mathrm{~mm} \times 8 \mathrm{~mm}$ were obtained after 10 days.

The sample was prepared in slow evaporation method at room temperature. The FT-IR spectrum of the sample was recorded in the region near $4000-400 \mathrm{~cm}^{-1}$ using a BRUKER IFS-66v FT IR Spectrometer at a resolution of $1 \mathrm{~cm}^{-1}$ equipped with a MCT detector, a KBr beam splitter and glober source. The FT-Raman spectrum of bi-glycine hydrobromide is recorded on a BRUKER IFS-66v model interferometer equipped with FRA-106 FT Raman accessory in the $4000-100 \mathrm{~cm}^{-1}$ stokes region using the $1064 \mathrm{~nm}$ line of Nd-YAG laser for excitation operating at $200 \mathrm{mw}$ powers. The molecule bi-glycine hydrobromide was newly synthesized by Sampathkrishnan et al. ${ }^{18}$.

Computational detail: Whole calculation conducted were performed using density functional B3LYP method 6.31 $++\mathrm{G}(\mathrm{d}, \mathrm{p})$ basis set using Gaussian $03 \mathrm{~W}$ program package ${ }^{7}$ on a intel core i3/1.6 Ghz personal computer for the title compound. The Geometric optimization and calculation of other parameters were carried out $6.31++\mathrm{G}(\mathrm{d}, \mathrm{p})$ basis set. In DFT method it is observed that all the stationary points are minima ${ }^{8}$. The vibrational frequency is assigned by means of 
visual inspection using the Gauss view program. We have used NBO 3.1 program $^{9}$ in the Gaussian $03 \mathrm{~W}$ program package on a intel core i3/1.6 GHz personal computer. We have NBO calculation to under in intra molecular delocalization or hyper conjugation.

Non-linear optical effect: Non linear optical effects means, when it propagates through a material it changes the properties of the medium, such as the refractive index. In the recent year NLO materials play major role in the telecommunication, photonic, opto electronic technologies and optical computing ${ }^{10-12}$. Many organic NLO Materials composed of aromatic molecules that are substituted with $\pi$ electron donors and acceptors which exhibit intermolecular change transfer resulting in high SHG efficiency ${ }^{13}$.

The molecular structure of bi-glycine hydrobromide is shown in Fig. 1.

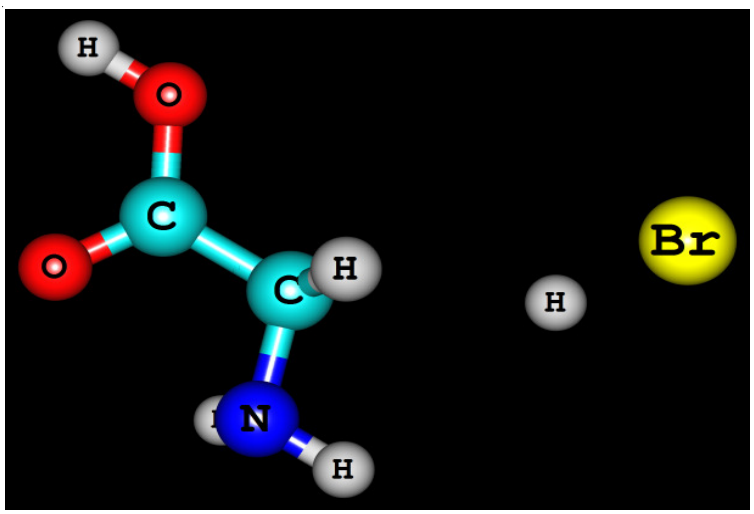

Fig. 1. Molecular structure of bi-glycine hydrobromide

The first hyperpolarizability $\left(\beta_{0}\right)$ of this novel molecular system and the related properties $\left(\beta_{0}, \alpha_{0}\right)$ of bi-glycine hydrobromide are calculated by B3LYP method using $6.31++\mathrm{G}(\mathrm{d}, \mathrm{p})$ basis set, based on the finite-field approach. In the presence of electric field. The first hyper polarizability is a third-rank tensor that can be described by a $3 \times 3 \times 3$ matrix. The 27 components of the 3D matrix can be reduced to 10 components due to the Klein man symmetry ${ }^{14,15}$. It can be given in the lower tetrahedral. The components of $\beta$ are defined as the coefficients in the Taylor series expansion of the energy in the external electric field. When the external electric field is weak and homogenous, this expansion becomes.

$$
E=E^{o}-\mu_{\alpha} F_{\alpha}-1 / 2_{\alpha \beta} F_{\alpha} F_{\beta}-1 / 6 \beta_{\alpha} \beta_{\gamma} F_{\alpha} F_{\beta} F_{\gamma}+\ldots \ldots
$$

where $\mathrm{E}^{\circ}$ is the energy of the unperturbed molecules, $\mathrm{F}_{\alpha}$, the field at the orgin and $\mu_{\alpha}, \alpha_{\alpha} \beta$ and $\beta_{\alpha} \beta_{\gamma}$ are the components of dipole moment $\mu$, polarizability $\alpha$, mean polarizability $\Delta \mu$ and the first hyperpolarizabilities $\beta_{0}$ using the $\mathrm{x}, \mathrm{y}, \mathrm{z}$ components are defined as follows ${ }^{16,17}$.

$$
\begin{aligned}
& \mu=\mu x^{2}+\mu y^{2}+\mu z^{2}, \\
& \alpha_{0}=\frac{\alpha_{\mathrm{xx}}+\alpha_{\mathrm{yy}}+\alpha_{\mathrm{zz}}}{3}, \\
& \Delta \alpha=2^{\frac{1}{2}}\left[\left(\alpha_{\mathrm{xx}}-\alpha_{\mathrm{yy}}\right)^{2}+\left(\alpha_{\mathrm{yy}}-\alpha_{\mathrm{xx}}\right)^{2}+6 \alpha_{\mathrm{xx}}^{2}\right]^{\frac{1}{2}}, \\
& \beta=\left(\beta x^{2}+\beta y^{2}+\beta z^{2}\right)^{\frac{1}{2}},
\end{aligned}
$$

$$
\begin{gathered}
\beta_{x}=\beta_{x x x}+\beta_{x y y}+\beta_{x z z}, \\
\beta_{y}=\beta_{y y y}+\beta_{x x y}+\beta_{y z z}, \\
\beta_{z}=\beta_{z z z}+\beta_{x x z}+\beta_{y y z}
\end{gathered}
$$

Since the values of the polarizability $(\alpha)$ and first hyperpolarizability $(\alpha)$ di pole moment $(\mu)$ of Gaussian 03 output are reported in atomic units (a.u), the calculated values have been converted into electrostatic units $(\mathrm{esu})(\alpha$ : $1 \mathrm{a} . \mathrm{u}=0.1482$ $\times 10^{-12}$ esu, $\beta: 1$ a.u $=8.6393 \times 10^{-33}$ esu $)$.The total molecular dipole moment and mean first hyperpolarizabilty of BGHB is 3.6186 Debye and $1.12525 \times 10^{-30}$ esu respectively shown in Table-1. Total dipole moment of BGHB is approximately three times greater than that of urea. This is how non-linear properties of the molecule is confirmed.

\begin{tabular}{cccc}
\multicolumn{5}{c}{ TABLE-1 } \\
\multicolumn{5}{c}{ CALCULATED ALL $\beta$ COMPONENTS } \\
AND $\beta_{\text {tot }}$ VALUE OF BI-GLYCINE HYDROBROMIDE \\
\hline Parameters & B3LYP & Parameters & B3LYP \\
\hline$\mu_{\mathrm{x}}$ & 0.9191 & $\beta_{\mathrm{xxx}}$ & 97.0153 \\
$\mu_{\mathrm{y}}$ & -0.7357 & $\beta_{\mathrm{xxy}}$ & -47.733 \\
$\mu_{z}$ & 1.3518 & $\beta_{\mathrm{xyy}}$ & 5.8408 \\
$\mu$ & 3.2132 & $\beta_{\mathrm{yyy}}$ & -12.4371 \\
$\alpha_{\mathrm{xx}}$ & 59.9763 & $\beta_{\mathrm{xxz}}$ & 10.1911 \\
$\alpha_{\mathrm{xy}}$ & 9.1025 & $\beta_{\mathrm{xyz}}$ & -7.5744 \\
$\alpha_{\mathrm{yy}}$ & 46.1545 & $\beta_{\mathrm{yyz}}$ & 7.2344 \\
$\alpha_{\mathrm{xz}}$ & -3.504 & $\beta_{\mathrm{xzz}}$ & 16.083 \\
$\alpha_{\mathrm{yz}}$ & 3.0188 & $\beta_{\mathrm{yzz}}$ & -2.6536 \\
$\alpha_{\mathrm{zz}}$ & 49.7463 & $\beta_{z z z}$ & 1.7944 \\
$\alpha(\mathrm{esu})$ & $.077 \times 10^{-10}$ & $\beta_{0}(\mathrm{esu})$ & $1.738 \times 10^{-30}$ \\
$\Delta \alpha(\mathrm{esu})$ & $1.8104 \times 10^{-30}$ & - & - \\
\hline
\end{tabular}

\section{RESULTS AND DISCUSSION}

Sampathkrishnan et al. ${ }^{18}$ determined the crystal structure of BGHB $\left[\left(\mathrm{C}_{2} \mathrm{H}_{5} \mathrm{NO}_{2}\right)_{2} \mathrm{Hbr}\right]$ which is non-centro symmetric space group $\mathrm{P} 2{ }_{1} 2_{1} 2_{1}$, with the cell dimension $\mathrm{a}=5.39 \AA$, $\mathrm{b}=$ $8.18 \AA, c=18.39 \AA, \alpha=90.18 \AA, \beta=89.88 \AA, \gamma=89.99^{\circ} \mathrm{V}$ $=812.43$. The optimized geometrical parameters (bond lengths and angels) by DFT, B3LYP with $6.311++\mathrm{G}(\mathrm{d}, \mathrm{p})$ as basis set are listed in Table-2. It is found that $\mathrm{N}_{2}-\mathrm{H}_{6}$ bond length is very high and its corresponding value is $2.6402 \AA$. This clearly indicates that $\mathrm{O}_{5}-\mathrm{H}_{2}$ occupy the low energy value. The next higher bond length value is $1.5132 \AA$. These values are found for $\mathrm{N} 2-\mathrm{C}_{3}, \mathrm{H} 6-\mathrm{Br} 7$ and $\mathrm{C} 1-\mathrm{O} 5$ and are $1.4228 \AA, 1.4232 \AA$, $1.3595 \AA$, respectively. For the title compound the N-H group bond length is found at the range 2.6402-1.0022 (i.e., $\mathrm{N}_{2}-\mathrm{H}_{6}$, $\mathrm{N}_{2}-\mathrm{H}_{8}, \mathrm{~N}_{2}-\mathrm{H}_{9}$ are 2.6402, 1.0021, $1.0022 \AA$ respectively). It shows that the N-H bond occupies in the higher energy level. The least bond length value is 0.972 . The bond lengths a value clearly indicates that this amino group are at the higher energy level.

For the title compound, the higher bond angle is found at C3-C1-O4, O4-C1-O5, C1-C3-N2, N2-C3-H10, H8-N2-H9 and their corresponding values are $128.72^{\circ}, 117.30^{\circ}, 115.50^{\circ}$, $109.08^{\circ}$ and $108.76^{\circ}$ respectively. The least bond angle value is $106.69^{\circ}$ and it is found at H6-N2-H8.

Vibrational band assignments: The maximum number of potentially active observable fundamental non-linear molecules, which contains $\mathrm{N}$ atoms, is equal to $(3 \mathrm{~N}-6)$ a part from 


\begin{tabular}{|c|c|c|c|}
\hline \multicolumn{4}{|c|}{$\begin{array}{c}\text { TABLE-2 } \\
\text { OPTIMIZED GEOMETRICAL PARAMETERS OF BGHB } \\
\text { OBTAINED BY B3LYP/6-31 ++G(d,p) DENSITY } \\
\text { FUNCTIONAL CALCULATIONS }\end{array}$} \\
\hline Bond length & Value $(\AA)$ & Bond angle & Value $\left({ }^{\circ}\right)$ \\
\hline $\mathrm{C}_{1}-\mathrm{C}_{3}$ & 1.5132 & $\mathrm{C}_{3}-\mathrm{C}_{1}-\mathrm{O}_{4}$ & 128.7253 \\
\hline $\mathrm{C}_{1}-\mathrm{O}_{4}$ & 1.2346 & $\mathrm{C}_{3}-\mathrm{C}_{1}-\mathrm{O}_{5}$ & 113.9657 \\
\hline $\mathrm{C}_{1}-\mathrm{O}_{5}$ & 1.3595 & $\mathrm{O}_{4}-\mathrm{C}_{1}-\mathrm{O}_{5}$ & 117.3089 \\
\hline $\mathrm{N}_{2}-\mathrm{C}_{3}$ & 1.4338 & $\mathrm{C}_{3}-\mathrm{N}_{2}-\mathrm{H}_{6}$ & 111.3589 \\
\hline $\mathrm{N}_{2}-\mathrm{H}_{6}$ & 2.6402 & $\mathrm{C}_{3}-\mathrm{N}_{2}-\mathrm{H}_{8}$ & 111.258 \\
\hline $\mathrm{N}_{2}-\mathrm{H}_{8}$ & 1.0021 & $\mathrm{C}_{3}-\mathrm{N}_{2}-\mathrm{H}_{9}$ & 111.226 \\
\hline $\mathrm{N}_{2}-\mathrm{H}_{9}$ & 1.0022 & $\mathrm{H}_{6}-\mathrm{N}_{2}-\mathrm{H}_{8}$ & 106.6981 \\
\hline $\mathrm{C}_{3}-\mathrm{H}_{10}$ & 1.1281 & $\mathrm{H}_{6}-\mathrm{N}_{2}-\mathrm{H}_{9}$ & 107.3429 \\
\hline $\mathrm{C}_{3}-\mathrm{H}_{11}$ & 1.1285 & $\mathrm{H}_{8}-\mathrm{N}_{2}-\mathrm{H}_{9}$ & 108.7602 \\
\hline $\mathrm{O}_{5}-\mathrm{H}_{12}$ & 0.972 & $\mathrm{C}_{1}-\mathrm{C}_{3}-\mathrm{N}_{2}$ & 115.5028 \\
\hline $\mathrm{H}_{6}-\mathrm{Br}_{7}$ & 1.4232 & $\mathrm{C}_{1}-\mathrm{C}_{3}-\mathrm{H}_{10}$ & 107.5272 \\
\hline- & - & $\mathrm{C}_{1}-\mathrm{C}_{3}-\mathrm{H}_{11}$ & 107.3932 \\
\hline- & - & $\mathrm{N}_{2}-\mathrm{C}_{3}-\mathrm{H}_{10}$ & 109.0846 \\
\hline- & - & $\mathrm{N}_{2}-\mathrm{C}_{3}-\mathrm{H}_{11}$ & 109.1495 \\
\hline- & - & $\mathrm{H}_{10}-\mathrm{C}_{3}-\mathrm{H}_{11}$ & 107.9329 \\
\hline- & - & $\mathrm{C}_{1}-\mathrm{O}_{5}-\mathrm{H}_{12}$ & 109.7263 \\
\hline - & - & $\mathrm{N}_{2}-\mathrm{H}_{6}-\mathrm{Br}_{7}$ & 167.9443 \\
\hline
\end{tabular}

three translational and three rotational degrees of freedom ${ }^{19,20}$. The intention of the vibrational analysis is to find vibrational modes connected with specific molecular structure of calculated compound. We have using density functional theory B3LYP level with the $6.311++\mathrm{G}(\mathrm{d}, \mathrm{p})$ basis set to calculated the vibration frequency of FT-IR,FT Raman spectra. The intricate information of vibration assignment of fundamental modes are shown in Table-3. The observed experimental FT-IR and FT-Raman spectra and simulated IR and Raman spectra at DFT B3LYP level with the $6.31++\mathrm{G}(\mathrm{d}, \mathrm{p})$ basis set are shown in Figs. 2 and 3.

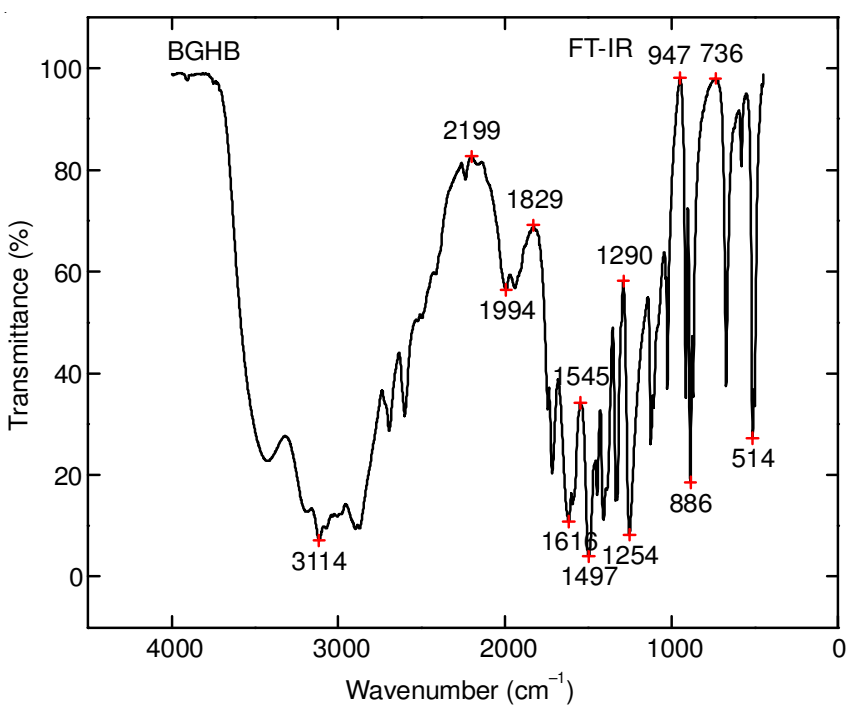

Fig. 2. Observed IR spectrum

Amino group vibrations: In associated aliphate and alicylcic primary amines, the $\mathrm{NH}_{2}$ antisymmetric stretching vibration occurs ${ }^{19-21}$. In dilute solution or in the vapour state, the $v_{\text {as }} \mathrm{NH}_{2}$ appears $^{22}$. Aliphatic and alicyclic primary amines in the associated state display $\mathrm{v}_{\mathrm{as}} \mathrm{NH}_{2}$ in the region $3290 \pm 30$ $\mathrm{cm}^{-1}$ and at $3350 \pm 40 \mathrm{~cm}^{-1}$ in a gas or in dilute solution. In the vibration spectra of copper complexes of L-asparagine and

\begin{tabular}{|c|c|c|c|c|}
\hline \multicolumn{5}{|c|}{$\begin{array}{l}\text { TABLE-3 } \\
\text { OBSERVED AND CALCULATION VIBRATIONAL OF BGHB AT } \\
\text { B3LYP METHOD WITH } 6.311++\mathrm{G}(\mathrm{d}, \mathrm{p}) \text { AND BASIS SETS }\end{array}$} \\
\hline \multirow{2}{*}{$\begin{array}{l}\text { Mode } \\
\text { nos }\end{array}$} & \multicolumn{2}{|c|}{$\begin{array}{c}\text { Observed } \\
\text { frequency }\left(\mathrm{cm}^{-1}\right)\end{array}$} & \multirow{2}{*}{$\frac{\text { Frequency }}{6.311+\mathrm{G}(\mathrm{d}, \mathrm{p})}$} & \multirow{2}{*}{ Assignment } \\
\hline & IR & Raman & & \\
\hline 1 & - & - & 3597 & $\mathrm{H}-\mathrm{N}-\mathrm{H}$ asymstr \\
\hline 1 & - & 3450 & - & H-N-H asymstr \\
\hline 2 & - & 3400 & 3409 & $\mathrm{H}-\mathrm{N}-\mathrm{H}$ asymstr \\
\hline 3 & - & - & 3323 & H-N-H asymstr \\
\hline 3 & 3114 & - & - & O-H Str \\
\hline 3 & - & 3027 & - & $\mathrm{H}-\mathrm{C} \alpha-\mathrm{H}$ str asym \\
\hline 3 & - & 3001 & - & $\mathrm{H}-\mathrm{C} \alpha-\mathrm{H}$ str asym \\
\hline 3 & - & 2984 & - & $\mathrm{H}-\mathrm{C} \alpha-\mathrm{H}$ str asym \\
\hline 3 & - & 2968 & - & $\mathrm{H}-\mathrm{C} \alpha-\mathrm{H}$ str asym \\
\hline 4 & - & - & 2799 & $\mathrm{H}-\mathrm{C} \alpha-\mathrm{H}$ str asym \\
\hline 5 & - & - & 2746 & $\mathrm{H}-\mathrm{C} \alpha-\mathrm{H}$ str asym \\
\hline 6 & 2199 & - & 2164 & $\mathrm{H}-\mathrm{C} \alpha-\mathrm{H}$ str asym \\
\hline 6 & - & 2000 & - & $\mathrm{H}-\mathrm{C} \alpha-\mathrm{H}$ str asym \\
\hline 6 & 1994 & - & - & $\mathrm{H}-\mathrm{C} \alpha-\mathrm{H}$ str asym \\
\hline 7 & - & 1713 & 1726 & $\mathrm{C}=\mathrm{O}$ \\
\hline 8 & - & - & 1602 & H-N-H Sciss \\
\hline 8 & - & 1590 & - & H-N-H Sciss \\
\hline 8 & 1545 & - & - & H-N-H Sciss \\
\hline 8 & 1497 & - & - & H-N-H Sciss \\
\hline 8 & - & 1490 & - & H-N-H Sciss \\
\hline 9 & - & 1445 & 1444 & OH Str \\
\hline 10 & - & - & 1412 & OH Str \\
\hline 10 & - & 1407 & - & $\mathrm{OH} \mathrm{Str}$ \\
\hline 10 & - & 1324 & - & $\mathrm{H}-\mathrm{C} \alpha-\mathrm{H}$ Wagg \\
\hline 10 & - & 1298 & - & H-C-H Twist \\
\hline 11 & - & - & 1294 & H-C $\alpha-H$ Twist \\
\hline 11 & 1290 & - & - & H-C $\alpha-H$ Wagg \\
\hline 12 & - & - & 1246 & H-C $\alpha-\mathrm{H}$ Wagg \\
\hline 12 & 1254 & - & - & $\mathrm{C}(=\mathrm{O}) \mathrm{O}$ \\
\hline 13 & - & - & 1185 & $\mathrm{C} \alpha-\mathrm{C}-\mathrm{O}$ asym str \\
\hline 13 & - & 1121 & - & H-N-H Twist \\
\hline 14 & - & - & 1100 & C-N Amine \\
\hline 14 & - & 1101 & - & C-N Amine \\
\hline 15 & - & - & 1070 & C-Cstr \\
\hline 15 & - & 1030 & - & C-Cstr \\
\hline 16 & - & - & 1015 & C-Cstr \\
\hline 16 & 947 & - & - & O-H-tor \\
\hline 16 & 886 & - & - & H-C $\alpha-H-r o c k$ \\
\hline 16 & - & 884 & - & $\mathrm{H}-\mathrm{C} \alpha$-H-rock \\
\hline 16 & - & 870 & - & H-C-H rock \\
\hline 17 & - & - & 840 & C-O Str \\
\hline 18 & - & - & 798 & H-N-H Wagg \\
\hline 18 & 736 & - & - & $\mathrm{C}=\mathrm{O}$ \\
\hline 19 & - & - & 623 & $\mathrm{C}=\mathrm{O}$ amide \\
\hline 20 & - & - & 597 & $\mathrm{C}=\mathrm{O}$ amide \\
\hline 20 & 514 & - & - & $\mathrm{H}-\mathrm{C} \alpha-\mathrm{H}$ rock \\
\hline 20 & - & 513 & - & H-C $\alpha-H$ rock \\
\hline 21 & - & - & 511 & $\mathrm{C}(=\mathrm{O}) \mathrm{O}$ \\
\hline 22 & - & - & 470 & $\mathrm{C}(=\mathrm{O}) \mathrm{O}$ \\
\hline 23 & - & - & 455 & $\mathrm{C}(=\mathrm{O}) \mathrm{O}$ \\
\hline 24 & - & - & 450 & $\mathrm{C}(=\mathrm{O}) \mathrm{O}$ \\
\hline 25 & - & - & 351 & $\mathrm{C} \alpha-\mathrm{C}-\mathrm{C}$ sciss \\
\hline 25 & - & 342 & - & $\mathrm{C} \alpha-\mathrm{C}-\mathrm{C}$ sciss \\
\hline 26 & - & - & 265 & N-H Tor \\
\hline 26 & - & 149 & - & $\mathrm{H}-\mathrm{N}-\mathrm{H}$ rock \\
\hline 27 & - & - & 125 & H-N-H rock \\
\hline 27 & - & 81 & - & $\mathrm{O}=\mathrm{C}-\mathrm{O}$ twist \\
\hline 28 & - & - & 53 & $\mathrm{O}=\mathrm{C}-\mathrm{O}$ twist \\
\hline 29 & - & - & 47 & $\mathrm{O}=\mathrm{C}-\mathrm{O}$ twist \\
\hline 30 & - & - & 38 & $\mathrm{O}=\mathrm{C}-\mathrm{O}$ twist \\
\hline
\end{tabular}




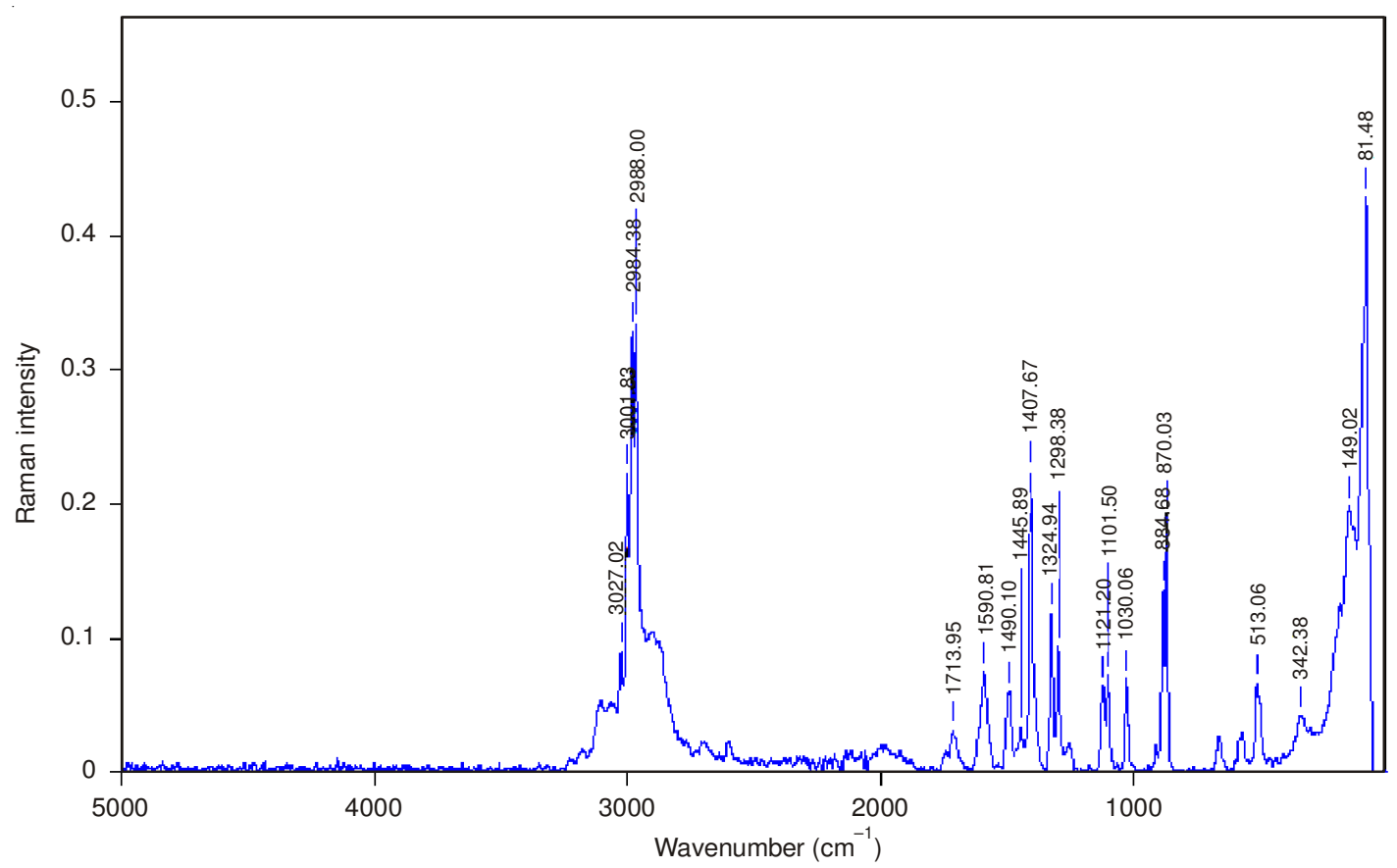

Fig. 3. Observed FTIR spectrum

L-glycine the $v_{\text {as }} \mathrm{NH}_{2}$ amino is reported at $3265,3278 \mathrm{~cm}^{-1}$ in the IR spectrum ${ }^{23}$. For this title compound we have observed $v_{\text {as }} \mathrm{NH}_{2}$ amino $3400 \mathrm{~cm}^{-1}$ (Raman) and 3409, $3323 \mathrm{~cm}^{-1}$ theoretically.

The $\mathrm{NH}_{2}$ scissoring vibration ${ }^{22}$ give rise to a broad strong band in the region $1600 \pm 50 \mathrm{~cm}^{-1}$. The title compound observed $1590 \mathrm{~cm}^{-1}$ (Raman) $1602 \mathrm{~cm}^{-1}$ theoretically. According to Roeges ${ }^{22}$ the rocking, twisting $\mathrm{NH}_{2}$ mode is expected in the region $1160 \pm 140 \mathrm{~cm}^{-1}$. The title compound reported $\mathrm{NH}_{2}$ twist $\left(1121 \mathrm{~cm}^{-1}\right)$. The band $1298 \mathrm{~cm}^{-1}$ (Raman), $1290 \mathrm{~cm}^{-1}$ (IR), $1246 \mathrm{~cm}^{-1}$ theoretically is assigned $\omega / \tau \mathrm{NH}_{2}$ for BGHB.

The primary amines show a characteristic very broad diffuse $\omega \mathrm{NH}_{2}$ band between $1000 \mathrm{~cm}^{-1}$ and $700 \mathrm{~cm}^{-1}$, with a maximum absorption at $840 \pm 55 \mathrm{~cm}^{-1}$. For the title compound $870 \mathrm{~cm}^{-1}$ (Raman), $798 \mathrm{~cm}^{-1}$ observed in theoretically. The $\mathrm{NH}_{2}$ torsion is expected in the region $290 \pm 130 \mathrm{~cm}^{-1}$ and in $\alpha$-saturated amines the region ${ }^{21,24}$ is reduced to $280 \pm 70 \mathrm{~cm}^{-1}$. Medium to weak absorption band in the unconjugated C-N linkage in primary, secondary and tertiary aliphatic amines ${ }^{25}$, appear in the region of $1250-1020 \mathrm{~cm}^{-1}$. The vibrations responsible for these bands involve $\mathrm{C}-\mathrm{N}$ stretching coupled with the stretching of adjacent bonds in the molecule. Baran et al. ${ }^{23}$ reported a value at around $1129 \mathrm{~cm}^{-1}$ as C-N amino stretching frequency. For the title compound the band at $1101 \mathrm{~cm}^{-1}$ (Raman) $1100 \mathrm{~cm}^{-1}$ and $1070 \mathrm{~cm}^{-1}$ (DFT) is assigned as $v(\mathrm{C}-\mathrm{N})$ mode.

COOH group vibrations: The $-\mathrm{C}(=\mathrm{O}) \mathrm{OH}$ group is best characterized by the $\mathrm{OH}$ stretch, the $\mathrm{C}=\mathrm{O}$ stretch and the $\mathrm{OH}$ out-of-plane deformation and even by the $\mathrm{C}-\mathrm{O}$ stretch and the $\mathrm{OH}$ in-plane deformation. The $\mathrm{C}=\mathrm{O}$ stretching vibration in the spectra of carboxylic acid gives rise to strong band in the region $1725 \pm 65 \mathrm{~cm}^{-1}$. In the present case $1713 \mathrm{~cm}^{-1}$ (Raman) and $1726 \mathrm{~cm}^{-1}$ (DFT) is observed as $\mathrm{C}=\mathrm{O}$ carboxyl.

The $\mathrm{OH}$ in-plane deformation, coupled to the $\mathrm{C}-\mathrm{O}$ stretching vibration is expected in the region $1390 \pm 55 \mathrm{~cm}^{-1}$. For the title compound $1445 \mathrm{~cm}^{-1}$ (Raman) $1407 \mathrm{~cm}^{-1}$ (Raman), $1444 \mathrm{~cm}^{-1}$ and $1412 \mathrm{~cm}^{-1}$ (DFT) is observed. The $\mathrm{C}(=\mathrm{O})-\mathrm{O}$ stretching vibration, coupled to the $\mathrm{OH}$ in-plane deformation, exhibits a moderate to strong band in the region $1250 \pm 80 \mathrm{~cm}^{-1}$. The out-of-plane $\mathrm{OH}$ deformation ${ }^{26}$ exhibits a moderate band in the region $905 \pm 65 \mathrm{~cm}^{-1}$. For the title compound $947 \mathrm{~cm}^{-1}$ (IR) is observed. The $\mathrm{C}=\mathrm{O}$ in-plane deformation is weakly to moderately active in the region $725 \pm 95 \mathrm{~cm}^{-1}$. The title compound $736 \mathrm{~cm}^{-1}$ (IR) observed. Most carboxylic acids display $\mathrm{C}=\mathrm{O}$ in the region $595 \pm 85 \mathrm{~cm}^{-1}$ which is in the vicinity of that of methyl and ethyl esters $-\mathrm{C}(=\mathrm{O}) \mathrm{O}$ deformation or rock has a weak to moderate intensity and appears in the region $445 \pm$ $120 \mathrm{~cm}^{-1}$. The band $947 \mathrm{~cm}^{-1}$ (IR) is assigned as OH of carboxylic group. The deformation $\mathrm{C}=\mathrm{O}$ bands are calculated to be at $736 \mathrm{~cm}^{-1}$ (Raman) and $23 \mathrm{~cm}^{-1}, 597 \mathrm{~cm}^{-1}$ theoretically.

$\mathbf{C H}_{2}$ group vibrations: The asymmetric stretch $v_{\text {as }} \mathrm{CH}_{2}$ symmetric stretch $v_{\text {as }} \mathrm{CH}_{2}$, scissoring vibrations $\mathrm{CH}_{2}$ and wagging vibration $\mathrm{v}_{\mathrm{as}} \mathrm{CH}_{2}$ appear in the region $3000 \pm 85 \mathrm{~cm}^{-1}$, $2965 \pm 30,1455 \pm 55$ and $1350 \pm 85 \mathrm{~cm}^{-1}$ respectively ${ }^{22,27}$. Absorption arising from $\mathrm{C}-\mathrm{H}$ stretching in alkenes occurs in the general region ${ }^{25}$ of $3000-2840 \mathrm{~cm}^{-1}$. The position of the $\mathrm{C}-\mathrm{H}$ stretch vibrations are among the stable in the spectrum, for the four $\mathrm{CH}_{2}$ groups, the asymmetric $\mathrm{CH}_{2}$ stretch bands at 3027, 3001, 2984, $2968 \mathrm{~cm}^{-1}$ in the Raman spectrum. The in-plane deformations of $\mathrm{CH}_{2}$ bands are observed $1497 \mathrm{~cm}^{-1}$ (IR), $1490 \mathrm{~cm}^{-1}$ (Raman). The wagging mode of $\omega \mathrm{CH}_{2}$ group observed at $1324 \mathrm{~cm}^{-1}$ in the Raman spectrum. The twisting mode $\tau \mathrm{CH}_{2}$ group are observed $1298 \mathrm{~cm}^{-1}$ (Raman), $1290 \mathrm{~cm}^{-1}$ (IR), 1294 and $1246 \mathrm{~cm}^{-1}$ (DFT). The rocking modes ${ }^{22} \mathrm{\rho CH}_{2}$ is expected in the range $895 \pm 85 \mathrm{~cm}^{-1}$, the band at $886 \mathrm{~cm}^{-1}$ (IR), $884 \mathrm{~cm}^{-1}$ (Raman), $870 \mathrm{~cm}^{-1}$ (Raman) are assigned as $\rho \mathrm{CH}_{2}$ modes for the title compound. The torsional modes are seen in the low wave number range ${ }^{22}$.

Other vibrations: Baran et al. ${ }^{23}$ reported the $\mathrm{CC}$ stretching bands in the range $1117-870 \mathrm{~cm}^{-1}$ and $\mathrm{CC}$ bending modes below $400 \mathrm{~cm}^{-1}$. In this compound $1101 \mathrm{~cm}^{-1}, 1030 \mathrm{~cm}^{-1}$ (Raman) 
and $1070 \mathrm{~cm}^{-1}, 1051 \mathrm{~cm}^{-1}$ (DFT) are observed. The bending modes $\delta$ CCC is calculated to be at $342 \mathrm{~cm}^{-1}$ (Raman), 351 $\mathrm{cm}^{-1}$ (DFT) are observed.

NBO analysis: NBO analysis provides the most accurate possible 'natural Lewis structure' picture of $\Phi$, because all orbital detail are mathematically chosen to include the highest possible percentage of the electron density. A useful aspect of the NBO method is that it gives information about interaction in both filled and virtual orbital spaces that could enhance the analysis or intra and intermolecular interactions.

The second order Fock matrix was carried out to evaluate the donor-acceptor interactions in teh NBO analysis ${ }^{28}$. The inter actions result is a loss of occupancy from the localined NBO of the idealized Lewis sturecture into an empty non-Lewis orbital. For each donor (i) and acceptor (j), the stabilazation energy $E$ (2) associated with the delocalization $\mathrm{i} \rightarrow \mathrm{j}$ is estimated as

$$
E(2)+\Delta E_{i j}=q_{i} \frac{F_{i j}{ }^{2}}{\varepsilon_{j}-\varepsilon_{i}}
$$

where $\mathrm{q}_{\mathrm{i}}$ is the donor orbital occupancy and are $\varepsilon_{\mathrm{i}}$ and $\varepsilon_{\mathrm{j}}$ diagonal elements and $F(i, j)$ is the off diagonal NBO Fock matrix element.

Natural bond orbital analysis provides an efficient method for studying intra and intermolecular bonding and interaction among bonds and also provides a convenient basis for investigating charge transfer or conjugative interaction in molecular systems. Some electron donor orbital, acceptor orbital and the interacting stabilization energy resulted from the second order micro-disturbance theory ${ }^{29,30}$. The larger the $\mathrm{E}(2)$ value, the more intensive is the interaction between electron donors and electron acceptors, i.e. the more donating tendency from electron donors to electron acceptors and the greater the extent of conjugation of the whole system. Delocalization of electron density between occupied Lewis-type (bond or lone pair) NBO orbitals and formally unoccupied (antibond or Rydgberg) nonLewis NBO orbitals correspond to a stabilizing donor-acceptor interaction. NBO analysis has been performed on the molecule at the DFT/B3LYP/6.311++G(d,p) level in order to elucidate the intramolecular, rehybridization and delocalization of electron density within the molecule.

The intra-molecular interaction is formed by the orbital overlap between $\sigma\left(\mathrm{C}_{1}-\mathrm{C}_{3}\right)$ and $\sigma^{*}\left(\mathrm{C}_{1}-\mathrm{O}_{4}\right)$ which results into intramolecular charge transfer causing stabilization of the system. These interaction are observed as increase in electron density (ED) in C-C anti bonding orbital that weakness respective bonds ${ }^{31}$. The electron density of glycine $\mathrm{HBr}$ ring $\mathrm{C}_{3}-\mathrm{C}_{4}$ is 1.94e. The most important interaction in the title compound having lone pair $\mathrm{C}_{1}$ with anti-bonding $\mathrm{O}_{5}-\mathrm{H}_{12}$ and $\mathrm{C}_{1}-\mathrm{O}_{5}$, results the stabilization of 0.83 and $0.51 \mathrm{~kJ} / \mathrm{mol}$, respectively. The most important interaction in the title compound having lone pair $\mathrm{C}_{3}$ with anti-bonding $\mathrm{C}_{1}-\mathrm{O}_{5}$ results the stabilization of 0.56 $\mathrm{kJ} / \mathrm{mol}$. The most important interaction in the title compound having lone pair $\mathrm{N}_{2}$ with anti-bonding $\mathrm{C}_{3}-\mathrm{H}_{11}$ and $\mathrm{C}_{1}-\mathrm{C}_{3}$ results the stabilization of 7.72 and $1.36 \mathrm{~kJ} / \mathrm{mol}$, respectively. The most important interaction in the title compound having lone pair $\mathrm{O}_{4}$ with anti-bonding $\mathrm{C}_{1}-\mathrm{O}_{5}$ and $\mathrm{C}_{1}-\mathrm{C}_{3}$ results the stabilization of 33.31 and $19.64 \mathrm{~kJ} / \mathrm{mol}$, respectively. The most important interaction in the title compound having lone pair $\mathrm{O}_{5}$ with anti-bonding $\mathrm{C}_{1}-\mathrm{O}_{4}$ and $\mathrm{C}_{1}-\mathrm{C}_{3}$ results the stabilization of 1.11 and $0.90 \mathrm{~kJ} / \mathrm{mol}$, respectively. The $\mathrm{E}^{(2)}$ value is chemically significant and can be used as a measure of the intramolecular delocalization and these results are presented in Table-4.

\section{TABLE -4}

SECOND-ORDER PERTURBATION THEORY ANALYSIS OF FOCK MATRIX IN NBO BASIS CORRESPONDING TO THE INTRAMOLECULAR OF BGHB

\begin{tabular}{|c|c|c|c|c|}
\hline $\begin{array}{c}\text { Donor } \\
\text { NBO (i) }\end{array}$ & $\begin{array}{l}\text { Acceptor } \\
\text { NBO (j) }\end{array}$ & $\begin{array}{c}\mathrm{E}^{(2) \mathrm{a}} \\
(\mathrm{kJ} / \mathrm{mol})\end{array}$ & $\begin{array}{c}\mathrm{E}(\mathrm{j})-\mathrm{E}(\mathrm{i})^{\mathrm{b}} \\
\text { (a.u.) }\end{array}$ & $\begin{array}{l}F(i, j)^{c} \\
\text { (a.u.) }\end{array}$ \\
\hline$\sigma\left(C_{1}-C_{3}\right)$ & $\sigma^{*}\left(\mathrm{C}_{1}-\mathrm{O}_{4}\right)$ & 0.90 & 1.25 & 0.030 \\
\hline$\sigma\left(\mathrm{C}_{1}-\mathrm{O}_{4}\right)$ & $\sigma^{*}\left(C_{1}-C_{3}\right)$ & 1.27 & 1.48 & 0.039 \\
\hline$\sigma\left(\mathrm{C}_{1}-\mathrm{O}_{5}\right)$ & $\sigma^{*}\left(\mathrm{~N}_{2}-\mathrm{C}_{3}\right)$ & 0.61 & 1.35 & 0.026 \\
\hline$\sigma\left(\mathrm{N}_{2}-\mathrm{C}_{3}\right)$ & $\sigma^{*}\left(C_{1}-C_{3}\right)$ & 0.54 & 1.12 & 0.022 \\
\hline$\sigma\left(\mathrm{N}_{2}-\mathrm{H}_{8}\right)$ & $\sigma^{*}\left(C_{1}-C_{3}\right)$ & 3.66 & 0.99 & 0.055 \\
\hline$\sigma\left(\mathrm{N}_{2}-\mathrm{H}_{9}\right)$ & $\sigma^{*}\left(\mathrm{C}_{3}-\mathrm{H}_{10}\right)$ & 3.04 & 1.01 & 0.050 \\
\hline$\sigma\left(\mathrm{C}_{3}-\mathrm{H}_{10}\right)$ & $\sigma^{*}\left(\mathrm{C}_{1}-\mathrm{O}_{4}\right)$ & 1.61 & 1.10 & 0.038 \\
\hline$\sigma\left(\mathrm{O}_{5}-\mathrm{H}_{12}\right)$ & $\sigma^{*}\left(\mathrm{C}_{1}-\mathrm{C}_{3}\right)$ & 4.07 & 1.16 & 0.062 \\
\hline $\mathrm{LP}_{2} \mathrm{C}_{1}$ & $\sigma^{*}\left(\mathrm{O}_{5}-\mathrm{H}_{12}\right)$ & 0.83 & 10.61 & 0.084 \\
\hline $\mathrm{LP}_{2} \mathrm{C}_{1}$ & $\sigma^{*}\left(\mathrm{C}_{1}-\mathrm{O}_{5}\right)$ & 0.51 & 10.55 & 0.67 \\
\hline $\mathrm{LP}_{2} \mathrm{C}_{3}$ & $\sigma^{*}\left(\mathrm{C}_{1}-\mathrm{O}_{5}\right)$ & 0.56 & 10.45 & 0.070 \\
\hline LP2N2 & $\sigma^{*}\left(\mathrm{C}_{3}-\mathrm{H}_{11}\right)$ & 7.72 & 0.67 & 0.064 \\
\hline LP2N2 & $\sigma^{*}\left(C_{1}-C_{3}\right)$ & 1.36 & 0.65 & 0.027 \\
\hline $\mathrm{LP}_{2} \mathrm{O}_{4}$ & $\sigma^{*}\left(\mathrm{C}_{1}-\mathrm{O}_{5}\right)$ & 33.31 & 0.60 & 0.128 \\
\hline $\mathrm{LP}_{2} \mathrm{O}_{4}$ & $\sigma^{*}\left(\mathrm{C}_{1}-\mathrm{C}_{3}\right)$ & 19.64 & 0.63 & 0.101 \\
\hline $\mathrm{LP}_{2} \mathrm{O}_{5}$ & $\sigma^{*}\left(\mathrm{C}_{1}-\mathrm{O}_{4}\right)$ & 8.19 & 1.11 & 0.085 \\
\hline $\mathrm{LP}_{2} \mathrm{O}_{5}$ & $\sigma^{*}\left(\mathrm{C}_{1}-\mathrm{C}_{3}\right)$ & 0.90 & 0.90 & 0.026 \\
\hline
\end{tabular}

$\mathrm{E}^{(2) a}$ means energy of hyperconjugative interaction; ${ }^{b}$ Energy difference between donor and acceptor $\mathrm{i}$ and $\mathrm{j}$ NBO orbital; ${ }^{\mathrm{c}} \mathrm{F}(\mathrm{i}, \mathrm{j})$ is the Fock matrix element between $i$ and $j \mathrm{NBO}$ orbitals

HOMO and LUMO analysis: The higher occupied molecular orbital (HOMO) and lowest un occupied molecular orbital (LUMO) are the main orbital take part in chemical stability ${ }^{32}$. The HOMO represents the ability to donate an electron LUMO as an electron acceptor represents the ability to obtain an elec$\operatorname{tron}^{33}$. The electron transition absorption corresponds to the transition from the ground to the first excited state and is mainly described by an electron excitation from the HOMO to the LUMO.HOMO and LUMO energies calculated by B3LYP/ $6.311++\mathrm{G}(\mathrm{d}, \mathrm{p})$ method as shown below The plots of highest HOMO and LUMO are shown in Fig. 4.

HOMO energy $($ B3LYP $)=-11.724 \mathrm{eV}$

LUMO energy $(B 3 L Y P)=0.399 \mathrm{eV}$

HOMO-LUMO energy gap $($ B3LYP $)=12.123 \mathrm{eV}$

Mulliken atomic charges: Mulliken atomic charge calculation has an important role in the application of quantum chemical calculation to molecular system ${ }^{34}$. Because of atomiccharges affect dipole moment, polarizability, electronic structure and more a lot of properties of molecular systems. The calculated mulliken charge values are listed in Table-5. The charge values with 6-31 ++G(d,p) basis set due to polarization.

The charge of $\mathrm{C}_{3}$ atom is 0.502 electrons for BGHB molecule. In amino group, the $\mathrm{H}_{5}$ and $\mathrm{H}_{4}$ atom accommodate less positive charge and become less acidic. These lead to $\mathrm{C}_{3}$ and $\mathrm{C}_{4}$ become high positive and become high acidic as compare to $\mathrm{C}_{2}$. 

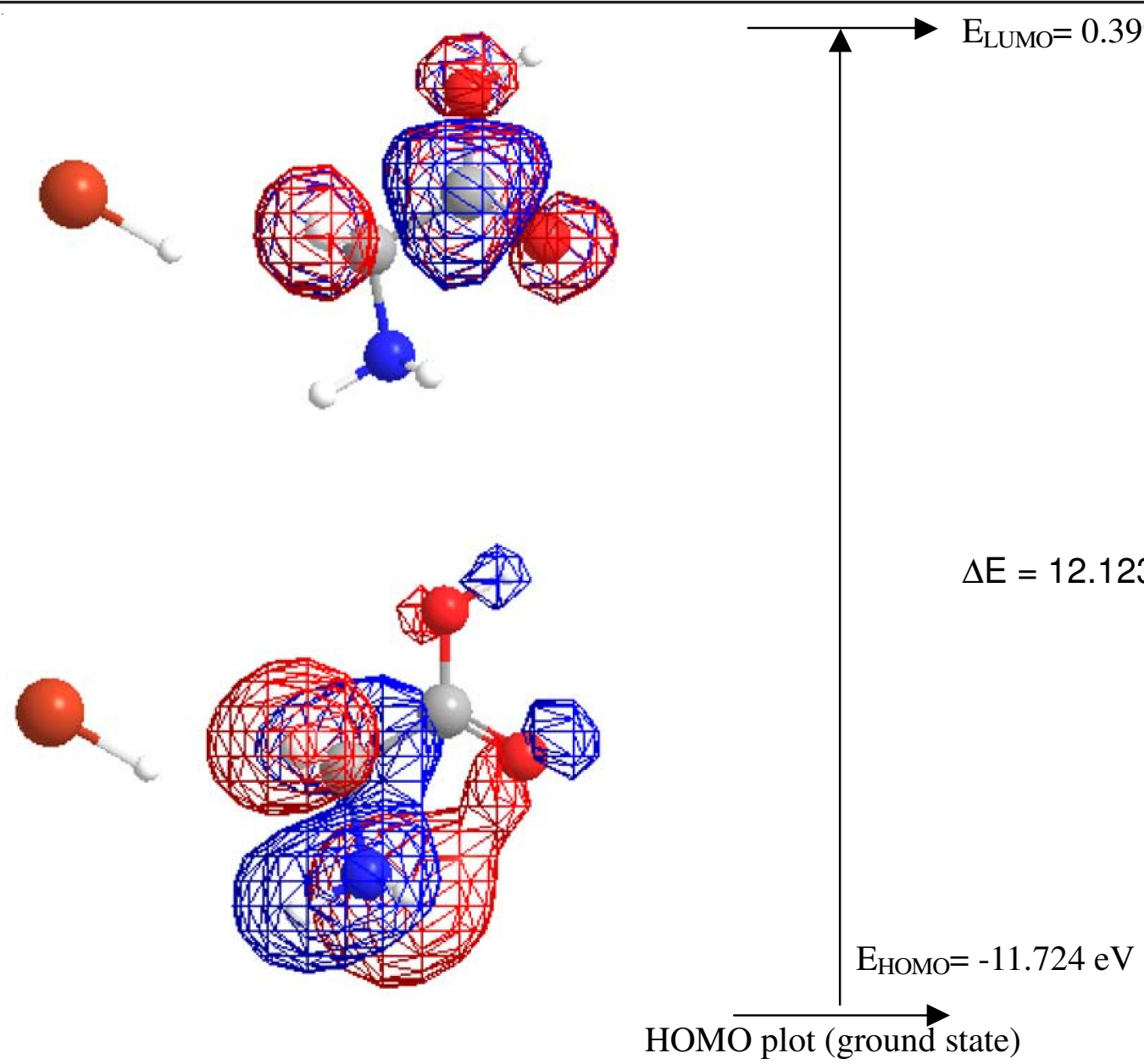

Fig. 4. Frontier molecular orbital (HOMO and LUMO) of Bi-glycine Hydrobromide. LUMO plot (first excited state)

\begin{tabular}{cccc}
\multicolumn{5}{c}{ TABLE-5 } \\
$\begin{array}{c}\text { ATOMIC CHARGE FOR OPTIMIZED GEOMETRY } \\
\text { OF BGHB AT B3LYP/6.31++ G(d,p) LEVEL }\end{array}$ \\
\hline Atom No & Atomic charge (e) & Atom No & Atomic charge (e) \\
\hline C1 & 0.502 & H4 & 0.187 \\
N1 & -0.632 & H5 & 0.15 \\
C2 & -0.213 & H6 & 0.401 \\
O1 & -0.378 & $\mathrm{C} 3$ & 0.502 \\
O2 & -0.567 & N2 & -0.07 \\
H1 & 0.088 & $\mathrm{C} 4$ & 0.125 \\
Br1 & -0.1 & $\mathrm{O} 3$ & -0.378 \\
H2 & 0.273 & $\mathrm{O} 4$ & -0.166 \\
H3 & 0.288 & $\mathrm{Br} 2$ & -0.012 \\
\hline
\end{tabular}

Thermodynamic parameters: Over and above the thermodynamic parameters of BGHB is present in Table- 6 the basis of vibration analysis B3LYP/6.311++G(d,p) level at this scale factors have been recommended ${ }^{35}$ for an accurate prophecy in determining the Zero-point vibrations energy (ZPVE), rotational constants, dipole moment and entropy $S_{\text {vit }}(T)$. The vibration in the ZPVE's appeared to be insignificate.

\section{Conclusion}

The new organic NLO material from the amino acid family, viz. bi-glycine hydrobromide (BGHB) was grown by slow evaporation method. The crystal structure of BGHB is manifested using X-ray diffraction data. The FT-IR, FT-Raman spectra were recorded and detailed vibrational assignment

\section{TABLE-6}

THEORETICALLY COMPUTED ENERGIES (a.u.), ZERO-POINT VIBRATIONAL ENERGIES (Kcal mol-1), ROT ATIONAL CONSTANTS $(\mathrm{GHz})$, ENTROPIES $\left(\mathrm{cal} \mathrm{mol}^{-1} \mathrm{~K}^{-1}\right)$, DIPOLE MOMENT $(\mu)$ AND ROTATIONAL TEMPERATURE $(\mathrm{K})$

\begin{tabular}{lc}
\hline Thermo dynamical parameters & $\begin{array}{c}\text { B3LYP6-31G ++(d,p) } \\
\text { values }\end{array}$ \\
\hline Total energy & -419.6749 \\
Zero point energy (Joules/mol) & 245731.6 \\
(Kcal/Mpl) & 58.73127 \\
Rotational Constants & 4.30033 \\
& 0.49354 \\
Zero-point correction (Hartree/Particle) & 0.44454 \\
Thermal correction to energy & 0.093594 \\
Thermal correction to enthalpy & 0.100858 \\
Thermal correction to Gibbs free energy & 0.101803 \\
Entropy & 0.059111 \\
Total & \\
Translational & 58.44 \\
Rotational & 0.889 \\
Vibrational & 0.889 \\
Dipole moment & 56.662 \\
\hline
\end{tabular}

using DFT method with $6.31++(\mathrm{d}, \mathrm{p})$ basis set were presented for BGHB. The FT-IR and FT-Raman spectrum were theoretically and experimentally also correlated. Using theoretical spectrum, the bond angle and bond length were calculated. Dipole moment, mean polarizability and first order hyper 
polarizability were determined with which the non-linear optical behaviour of the title molecule was investigated. HOMO LUMO orbital localization and NBO analysis also confirmed these NLO properties with the help of intermolecular charge transfer.

\section{ACKNOWLEDGEMENTS}

The authors thanks to Thiru. Sarav Periasamy, Chairman, Thiru Sasi Veerarajan, Chief Operating Officer and Dr. Sendil Velan, Principal, PERI Insitute of Technology, Chennai for their encouragement throughout the work.

\section{REFERENCES}

1. A.K. Bhowmik, S. Tan, A.C. Ahyi, J.A, Dharmadhikari, A.K. Dharmadhikari and D. Mathur, Opt. Commun., 280, 472 (2007).

2. S.B. Monaco, L.E. Davis, S.P. Velsko, F.T. Wang, D. Eimerl and A.J. Zalkin, J. Cryst. Growth, 85, 252 (1987).

3. K. Meera, R. Muralidharan, R. Dhanasekaran, P. Manyum and P. Ramasamy, J. Cryst. Growth, 263, 510 (2004).

4. E.E.A. Shepherd, J.N. Sherwood, G.S. Simpson and C.S. Yoon, J. Cryst. Growth, 113, 360 (1991).

5. Ch. Bosshard, K. Sutter, R. Schiesser and P. Gunter, J. Opt. Soc. Am. $B, \mathbf{1 0}, 867$ (1993).

6. J. Wiesner, K. Fucik, K. Kettler, J. Sakowski, R. Ortmann, H. Jomaa and M. Schlitzer, Bioorg. Med. Chem. Lett., 13, 1539 (2003).

7. M.J. Frisch, G.W. Trucks, H.B. Schlegel, G.E. Scuseria, M.A. Robb, J.R. Cheeseman, J.A. Montgomery, Jr., T. Vreven, K.N. Kudin, J.C. Burant, J.M. Millam, S.S. Iyengar, J. Tomasi, V. Barone, B. Mennucci, M. Cossi, G. Scalmani, N. Rega, G.A. Petersson, H. Nakatsuji, M. Hada, M. Ehara, K. Toyota, R. Fukuda, J. Hasegawa, M. Ishida, T. Nakajima, Y. Honda, O. Kitao, H. Nakai, M. Klene, X. Li, J.E. Knox, H.P. Hratchian, J.B. Cross, V. Bakken, C. Adamo, J. Jaramillo, R. Gomperts, R.E. Stratmann, O. Yazyev, A.J. Austin, R. Cammi, C. Pomelli, J.W. Ochterski, P.Y. Ayala, K. Morokuma, G.A. Voth, P. Salvador, J.J. Dannenberg, V.G. Zakrzewski, S. Dapprich, A.D. Daniels, M.C. Strain, O. Farkas, D.K. Malick, A.D. Rabuck, K. Raghavachari, J.B. Foresman, J.V. Ortiz, Q. Cui, A.G. Baboul, S. Clifford, J. Cioslowski, B.B. Stefanov, G. Liu, A. Liashenko, P. Piskorz, I. Komaromi, R.L. Martin, D.J. Fox, T. Keith, M.A. Al-Laham, C.Y. Peng, A. Nanayakkara, M. Challacombe, P.M.W. Gill, B. Johnson, W. Chen, M.W. Wong, C. Gonzalez and J.A. Pople, Gaussian, Inc., Wallingford CT, Gaussian 03, Revision C.02 (2004).
8. H.B. Schlegel, J. Comput. Chem., 3, 214 (1982).

9. E.D. Glenderina, A.E, Read, J.E.Carpenter, F.Weinhold, NBO Version 3.1 TCI, University of Wisconsin, Madison, (1998).

10. M.D. Aggarwal, J. Stephens, A.K. Batra and R.B. Lal, J. Optoelectron. Adv. Mater, 5, 555 (2003).

11. E.M. Hampton, B.S. Shah and J.N. Sharwood, J. Cryst. Growth, 22, 22 (1974).

12. C.N. Nanev, Cryst. Res. Technol., 39, 3 (2004).

13. M.N. Bhat and S.M. Dharmaprakash, J. Cryst. Growth, 235, 511 (2002).

14. D.A. Kleinman, Phys. Rev., 126, 1977 (1962).

15. J. Karpagam, N. Sundaraganesan, S. Sebastian, S. Manoharan and M. Kurt, J. Raman Spectrosc., 41, 53 (2010).

16. R. Zhang, B. Du, G. Sun and Y.X. Sun, Spectrochim. Acta A, 75, 1115 (2010).

17. H. Tanak, J. Mol. Struct. (Theochem.), 950, 5 (2010).

18. S. Sampathkrishnan, N. Balamurugan, R. Kumutha, Y. Vidyalakshmi and S. Muthu, J. Miner. Mater. Chacter. Eng., 11, 597 (2012).

19. M. Silverstein, G. Clayton Bassler and C. Morril, Spectroscopic Identification of Organic Compounds, John Wiley, New York (1980).

20. E.B. Wilson, J.C. Decius and P.C. Cross, Molecular Vibrations, Dover Publications Inc., New York (1980).

21. L. Segal and F.V. Eggerton, Appl. Spectrosc., 15, 112 (1961).

22. N.P.G. Roeges, A Guide to the Complete Interpretation of Infrared Spectra or Organic Structure, Wiley, New York (1994).

23. E.J. Baran, I. Viera and M.H. Torre, Spectrochim. Acta A, 66, 114 (2007).

24. S.M. Cravan and F.F. Bentley, Appl. Spectrosc., 26, 449 (1971).

25. R.M. Silverstein and F.X. Webster, Spectrometric Identification of Organic Compounds, Wiley, Asia, edn 6 (2003).

26. I. Fischmeister, Spectrochim. Acta A, 20, 1071 (1964).

27. N.B. Colthup, L.H. Daly and S.E. Wiberly, Introduction to Infrared and Raman Spectroscopy, Academic Press, New York, edn 2 (1985).

28. M. Szafran, A. Komasa and E. Bartoszak-Adamska, J. Mol. Struct. Themochem., 827, 101 (2007).

29. A. James, A.A. Raj, R. Reghunathan, V.S. Jayakumar and I.H. Joe, J. Raman Spectrosc., 37, 1381 (2006).

30. J. Liu, Z. Chen and S. Yuan, J. Zhejiang Univ. Sci., 6B, 584 (2005).

31. S. Sebastian and N. Sundaraganesan, Spectrochim. Acta A, 75, 941 (2010).

32. S. Gunasekaran, R.A. Balaji, S. Kumerasan, G. Anand and S. Srinivasan, Can. J. Anal. Sci. Spectrosc., 53, 149 (2008).

33. E. Kavitha, N. Sundaraganesan and S. Sebstan, Indian J. Pure Appl. Phys., 48, 20 (2010).

34. V.K. Rastogi, M.A. Palafox, L. Mittal, N. Peica, W. Kiefer, K. Lang and S.P. Ojha, J. Raman Spectrosc, 38, 1227 (2007).

35. M. Alcolea Palafox, Int. J. Quantum Chem., 77, 661 (2000). 